\title{
1. The Categories \& Normative Science
}

For PEIRCE, philosophy is a theoretical science of discovery. Since it is scientific it deals with fact. Philosophy, in short, is a positive science differing from the more familiar positive sciences (physics, chemistry, etc.) only in this: that the facts with which it deals do not require any special training or equipment in order to be observed. Philosophy deals with ordinary facts of man's everyday existence, open to all at any time to observe. Peirce subdivides philosophy into phenomenology, normative science, and metaphysics. Phenomenology takes inventory of what appears without passing any judgment upon what it observes. It says neither "true" or "false" nor "good" or "bad" about the phenomena. ${ }^{1}$ One might say that, for Peirce, phenomenology merely observes and catalogs the contents of experience. Normative science evaluates and judges the data thus collected, while metaphysics tries to comprehend their reality. It is clear, therefore, that in some sense phenomenology is the most basic of the philosophical disciplines-the one without which the enterprise could not even begin. The categories which phenomenology provides will be the conceptual frame in which the other parts of philosophy will make their analyses and explanations. It is not surprising, therefore, that Peirce should tell James that the true nature of pragmatism cannot be understood without the categories (8.256), nor that Peirce himself employs them to elucidate his division of normative science (8.256, $1.121-124,5.129$ ). Since we are trying to understand the role of nor-

1 An objection might be raised at the outset, namely, that the categories themselves are involved in the phenomenological analysis. Peirce would probably reply that some categories are supposed in any analysis, but they need not be the universal ones.

Peirce also distinguishes two stages in philosophy: the heuristic and the retrospective. The first he calls "coenoscopy," the second "synthetic philosophy." ("Charles S. Peirce Papers," Houghton Library, Harvard University, \#283, pp. 13-15. These numbers are from R. S. Robin's Annotated Catalogue. Henceforth, references to the Peirce manuscripts will be as follows: Peirce Papers, \#283, pp. 13-15.) 
mative science in Peirce's pragmatism, we must consider briefly the relation of his categories to esthetics, ethics, and logic. ${ }^{2}$

To guide us in this rather intricate analysis, it would be well perhaps to anticipate one result of Peirce's phenomenological investigations, namely, his theory of how ideas may be separated, or to put it in more traditional terms, his theory of distinctions. According to him there are three grades of separability of one idea from another: (1) dissociation, (2) "prescission," and (3) distinction. By "dissociation" he means that one idea can be imagined without another, just as we can imagine the color red without imagining the color blue. By "prescission" he means that even when two ideas are so closely connected that we cannot imagine one without the other, we can sometimes suppose one without the other. Thus, for example, while one can neither imagine nor suppose color without space, one can suppose space without color even though our experience does not allow us to imagine uncolored space. In other words, although color and space are inseparable in our experientially-bound imagination, we can discern a logical priority of one over the other-in our example, that of the subject of inherence of a quality over the quality itself. By "distinction," Peirce means simply the power to discriminate between two ideas which cannot even be supposed one without the other, as for example, taller and shorter. The meanings here can be distinguished although not separated because they are strictly relative to one another. Peirce would probably also allow the nonmutual relation of quality to a subject of inherence as an example of what he means by "distinction" ( cf. 1.549 n. 1) even though it might be argued that the foundation for the discrimination is really in the fact that the subject can be prescinded from the quality (1.353). ${ }^{3}$

In these terms, then, what is the relationship of normative science

2 Cf. 5.39: "This science of Phenomenology, then, must be taken as the basis upon which normative science is to be erected . . . ."

3 Peirce sometimes refers to prescission as abstraction (1.549), but in a long note, he pinpoints "prescission" as one type of abstraction. He quotes Scotus as his authority on this matter and yet nowhere takes up the much more sophisticated set of distinctions-one mostly Thomistic, the other Scotistic-current in the medieval schools. It turns out that in the theory of distinctions lie the basic differences in the philosophies of these two schools; or perhaps more accurately, the differences in the theory of distinctions result from metaphysical differences. 
to phenomenology? They cannot be dissociated because normative science intrinsically depends upon phenomenology for its categorial structure. On the other hand, there is more than just a distinction between them, for phenomenology may be prescinded from normative science. The latter is a step beyond the former which perhaps need not be taken, but which cannot be taken without the former. Consequently, the categories precede normative science. But once normative science is investigated, it of course becomes part of the phenomena inventoried by phenomenology and so the categories must apply there too. In other words, while logical priority dictates that one begin with phenomenology and subsequently move on to normative science (and then to metaphysics), once normative science is born, there is a movement back again to phenomenology in order to classify (and so more fully to understand) the nature of the normative. This will become clearer as we proceed.

Let us begin then with a rapid description of Peirce's phenomenology, in order to get at his new categories. Peirce describes the role of this science as follows:

But before we can attack any normative science, any science which proposes to separate the sheep from the goats, it is plain that there must be a preliminary inquiry which shall justify the attempt to establish such dualism. This must be a science that does not draw any distinction of good and bad in any sense whatever, but just contemplates phenomena as they are, simply opens its eyes and describes what it sees; not what it sees in the real as distinguished from figmentnot regarding any such dichotomy-but simply describing the object, as a phenomenon, and stating what it finds in all phenomena alike. This is the science which Hegel made his starting-point, under the name of the Phänomenologie des Geistes-although he considered it in a fatally narrow spirit, since he restricted himself to what actually forces itself on the mind and so colored his whole philosophy with the ignoration of the distinction of essence and existence and so gave it the nominalistic and I might say in a certain sense the pragmatoidal character in which the worst of the Hegelian errors have their origin. I will so far follow Hegel as to call 
this science Phenomenology although I will not restrict it to the observation and analysis of experience but extend it to describing all the features that are common to whatever is experienced or might conceivably be experienced or become an object of study in any way direct or indirect. (5.37)

Although Peirce's phenomenological studies began under Kant's and not Hegel's influence (cf. e.g. 4.3, 4.4), he found that his conclusions and Hegel's were not so very different, at least in comparison with those of other philosophers. Hegel was right in making phenomenology bring out clearly the categories of fundamental modes of reality. $\mathrm{He}$ was again right in distinguishing between universal categories (all of which apply to everything) and limited categories (limited to various phases of evolution); it is with the former that we shall be engaged.

In regard to these [universal categories], it appears to me that Hegel is so nearly right that my own doctrine might very well be taken for a variety of Hegelianism, although in point of fact it was determined in my mind by considerations entirely foreign to Hegel, at a time when my attitude toward Hegelianism was one of contempt. There was no influence upon me from Hegel unless it was of so occult a kind as to entirely escape my ken; and if there was such an occult influence, it strikes me as about as good an argument for the essential truth of the doctrine, as is the coincidence that Hegel and I arrived in quite independent ways substantially to the same result. (5.38)

These universal categories, according to Peirce, are three in number, no more and no less, absolutely irreducible one to another yet interdependent, and directly observable in elements of whatever is at any time before the mind in any way. Firstness, Secondness, and Thirdness roughly correspond to the modes of being: possibility, actuality, and law (1.23). ${ }^{4}$

4 Cf. e.g., Peirce's letter to Lady Victoria Welby, Oct. 12, 1904 where he defines and explains at length Firstness, Secondness, and Thirdness. Charles S. Peirce's Letters to Lady Welby, ed. Irwin C. Lieb (New Haven: Whitlock's, 1953), pp. 7-14. 
The category most easily grasped is that of Secondness or actuality. It is typified in the experience of effort, of resistance, of struggle, of opposition. Actuality consists in a then and there, in a relation to other existents. Briefly, actuality is something brute-brute fact which shocks. There is no reason in it.

I instance putting your shoulder against a door and trying to force it open against an unseen, silent, and unknown resistance. We have a two-sided consciousness of effort and resistance, which seems to me to come tolerably near to a pure sense of actuality. (1.24)

Secondness is the category of experience. The breaking of the night's silence by a piercing whistle-the shock and surprise in it-reveals a two-sided consciousness of an ego and a non-ego. This is what experience is-what the course of life compels one to think. ${ }^{5}$ Firstness is characteristic of the mode of being which consists in its subject's being positively such as it is regardless of anything else (1.25).

For as long as things do not act upon one another there is no sense or meaning in saying that they have any being, unless it be that they are such in themselves that they may perhaps come into relation with others. The mode of being a redness, before anything in the universe was yet red, was nevertheless a positive qualitative possibility. And redness in itself, even if it be embodied, is something positive and sui generis. (1.25)

Thirdness, on the other hand, characterizes the mode of being of laws governing future events. It manifests itself in experience through predictions which have a decided tendency to be fulfilled. If a prediction has a decided tendency to be fulfilled it must be that future events have a tendency to conform to a general rule. For Peirce, this can only mean that generals or laws or Thirds are real.

"Oh," but say the nominalists, "this general rule is nothing but a mere word or couple of words!" I reply, "Nobody ever dreamed of denying that what is general is of the nature of a general sign; but the question is whether future events will

5 Letters to Welby, p. 8-9. 
conform to it or not. If they will, your adjective 'mere' seems to be ill-placed." (1.26)

Thirdness consists in the fact that future facts of Secondness will take on a determinate general character. It is clear, then, that Thirdness is characterized by its mediating role. Law, governing events, mediates between pure possibility (Firstness) and pure actuality (Secondness). Put in logical terms, Thirdness is always and exclusively a triadic relation.

Analyze for instance the relation involved in 'A gives B to C'. Now what is giving? It does not consist in A's putting B away from him and C's subsequently taking B up. It is not necessary that any material transfer should take place. It consists in A's making $\mathrm{C}$ the possessor according to Law. . . . But now suppose that giving did consist merely in A's laying down the $\mathrm{B}$ which $\mathrm{C}$ subsequently picks up. That would be a degenerate form of thirdness in which the thirdness is externally appended. In A's putting away B, there is no thirdness. In C's taking B, there is no thirdness. But if you say that these two acts constitute a single operation by virtue of the identity of B, you transcend the mere brute fact, you introduce a mental element. (Letter to Lady Victoria Welby, Lieb's ed., p. 8)

But to be (or at least to involve) a triadic relation is to be "of the nature of a general sign." In psychological terms, then, we might express the mediating role of Thirdness this way: Thirdness is the category of thought, mediating between the Firstness of feeling and the Secondness of reaction. Peirce gathers under Thirdness the following: triadic relations, thought, generals, and laws. They all involve a mental element and yet are real, not just figments of someone's mind. Therefore the mental or the realm of thought cannot be limited to a man's "consciousness" ( see 8.256). Thus it is that the category of Thirdness leads Peirce to a form of objective idealism which he calls synechism.

The above treatment, of course, is but the barest outline of

${ }^{6}$ Cf. Letters to Welby, pp. 9-14 for an extended development of the theory of signs. 


\section{PEIRCE ON NORMS AND IDEALS}

Peirce's categories. It will serve, however, to give us some idea of the schema. Now we must consider for a moment how Peirce conceives Firstness, Secondness, and Thirdness to be related to each other. On the one hand, it is clear that they are irreducible and omnipresent. They describe all phenomena. On the other hand, Peirce tells us explicitly that the categories are interdependent. In terms of the degrees of separability of ideas, Peirce explains that the categories cannot be dissociated in the imagination from each other, nor from other ideas. But one category can be prescinded from another in a definite order: Firstness can be prescinded from Secondness and Thirdness, Secondness can be prescinded from Thirdness, but Secondness cannot be prescinded from Firstness, nor Thirdness from Secondness. Of course, the categories can easily be distinguished, but still

... it is extremely difficult accurately and sharply to

distinguish each from other conceptions so as to hold it in its

purity and yet in its full meaning. (1.353)

Perhaps what Peirce has in mind is the fact that a true appreciation of the categories would require a thorough study of the logic of relatives. Peirce develops his categories in two ways, from "without" and from "within." The former is through phenomenology, the latter through the logic of relations. The "logical" approach to the categories is through an analysis of what is necessarily involved in representations and triadic relations. A thorough appreciation of the categories requires both-experience and logic. The categories themselves must not be confused with the elements in the categories: a First is not to be confused with Firstness, nor a Second with Secondness, nor a Third with Thirdness. There can be various combinations of category with category, and of element with category. It becomes intricate indeed and requires no little logical skill. While it is not to our purpose to pursue this important point at great length it might be well to discuss some of these combinations briefly.

Peirce tells us that Secondness and Thirdness are conceptions of complexity, although they are not complex conceptions (because they are ultimate and irreducible categories of being) (1.525). Take Secondness for example. Secondness is the category of reaction and so naturally we think of two objects interacting, a First and a Second. 
But it would be a logical mistake to look upon this dyadic relation as made up of three elements: the First, the Second, and their reaction. Secondness is not built up out of pieces; rather Secondness pervades the whole relationship. If an object is a Second, it is a Second precisely because it is in a dyadic relation to something else. It has an element of being what another makes it to be. A fortiori the same is true of the reaction itself. It is not another thing or object, but a fact about two objects (1.526). It follows, then, that one can talk about the Secondness of a Second and the Secondness of a First (where the First and Second are in a dyadic relation), and that the Secondness of the First need not be the same as the Secondness of the Second. Consider the Secondness of the relation of quality to the matter in which it inheres (Peirce's own illustration, 1.527). The quality in itself is a Firstness, a mere possibility. The relation of inherence does not change the quality in itself, but merely imparts to it existence. Its existence is nothing but the relation of inherence in matter. But the situation with regard to its matter is quite different. Matter has no being at all except as subject of qualities, that is to say, its relation to qualities constitutes its existence. Void of all qualities, matter would not only not exist, but it would have no definite possibility at allit would be unreal-it would be nothing at all.

Thus we have a division of seconds into those whose very being, or Firstness, it is to be seconds, and those whose Secondness is only an accretion. (1.528)

The reason is not difficult to find. Basically it is the same reason which allows one to prescind Firstness from Secondness and Thirdness, and Secondness from Thirdness: the very essence of those categories.

This distinction springs out of the essential elements of Secondness. For Secondness involves Firstness. The concepts of the two kinds of Secondness are mixed concepts composed of Secondness and Firstness. One is the second whose very Firstness is Secondness. The other is a second whose Secondness is second to a Firstness. (1.528)

Peirce remarks that this way of mingling Firstness and Secondness is distinct from the ideas of Firstness and Secondness which it combines, and so seems to form a different series of categories which, however, 
in turn, depend upon Firstness, Secondness, and Thirdness as component parts.

The idea of mingling Firstness and Secondness in this particular way is an idea distinct from the ideas of Firstness and Secondness which it combines. It appears to be a conception of an entirely different series of categories. At the same time, it is an idea of which Firstness, Secondness, and Thirdness are component parts, since the distinction depends on whether the two elements of Firstness and Secondness that are united are so united as to be one or whether they remain two. (1.528)

Thus arises Peirce's distinction between genuine and degenerate grades of Secondness. Genuine Secondness is the Secondness of genuine Seconds, or matters; degenerate Secondness is the Secondness of a Second whose mode of being in se is Firstness (quality, in our example). A similar analysis might be made of Thirdness, with the exception that it will be found to have two grades of degeneracy (1.529). Firstness, of course, cannot have such a distinction.

The categories themselves are capable of similar combinations, and that because of their very nature. Whenever you have a triplet, you have three pairs; where you have a pair, you have two units (1.530). This is why the categories are subject to "prescission" in a certain order (see above). Thus, for example, because Secondness is an essential part of Thirdness and Firstness is an essential part of both Secondness and Thirdness, there is a Firstness of Secondness and of Thirdness, and a Secondness of Thirdness, but there can be no Secondness of pure Firstness nor Thirdness of pure Firstness or Secondness.

When you strive to get the purest conceptions you can of Firstness, Secondness, and Thirdness, thinking of quality, reaction, and mediation-what you are striving to apprehend is pure Firstness, the Firstness of Secondness-that is what Secondness is, of itself-and the Firstness of Thirdness. When you contrast the blind compulsion in an event of reaction considered as something which happens and which of its nature can never happen again ... when, I say, you contrast 
this compulsion with the logical necessitation of meaning considered as something that has no being at all except so far as it actually gets embodied in an event of thought, and you regard this logical necessitation as a sort of actual compulsion, since the meaning must actually be embodied, what you are thinking of is a Secondness involved in Thirdness. (1.530)

Thus we have the following combinations:

1) Firstness of Firstness-quality in itself, or "possibility" (Primity)

2) Firstness of Secondness-existence or actuality (Secundity)

3) Firstness of Thirdness-mentality (Tertiality)

Taking Secondness we find:

1) Secondness of Secondness-reaction

2) Secondness of Thirdness-law as actual compulsion

Finally Thirdness gives us:

1) Thirdness of Thirdness-generality, lawfulness, reasonableness. $^{7}$

Since Thirdness is the most important category for a philosophical analysis and classification of sciences, let us consider it a little more closely. Wherever there is Thirdness, according to Peirce, there is a First, a Second and a Third (a triadic relation). The First is a positive qualitative possibility; the Second is an existent thing determined by that First; and the Third is a law, or concept, which determines the relation between the First and Second (1.536). But Thirdness has a genuine and two degenerate forms. In genuine thirdness, the First, the Second, and the Third are all of the nature of Thirds, or thought. They are First, Second, and Third only relatively to each: the First is thought in its capacity as mere possibility (mind capable of thinking);

7 Of course these same divisions could be ordered in another way: Firstness of Firstness Firstness of Secondness Firstness of Thirdness Secondness of Secondness Secondness of Thirdness Thirdness of Thirdness 
the Second is thought as an event (actual thinking experience or information); the Third is thought insofar as it brings information into the mind (informing thought or cognition) (1.537).

Peirce sees in this relationship between a First, a Second and a Third, the operation of a sign, and in terms of the elements in a sign he explains the two degenerate grades of Thirdness. First of all, a sign stands for something other than itself; but that other for which it stands can itself only be another sign. The reason is that if the sign is to be affected by the object, "the object must be able to convey thought, that is, must be of the nature of thought or of a sign" (1.538). Every thought is a sign. In the first degree of degeneracy, however, the Thirdness affects the object, whereas in genuine Thirdness the sign is only affected by the object. What happens is that the Third brings about a Secondness which it regards as nothing more than a fact. Peirce calls it the execution of an intention. In the last degree of degeneracy there is thought, "but no conveyance or embodiment of thought at all" (1.538). It is merely the apprehension of a fact according to a possible idea. Peirce calls it instigation without prompting. ${ }^{8}$ He gives the example of one's saying "this object is red." If the speaker is asked to justify his judgment, he might say, "I saw it was red." But that is not accurate. What was seen was simply an image, with no subject or predicate in it, not in the least like a proposition. The image instigated the judgment owing to the possibility of thought. ${ }^{9}$

Peirce applied his categorial scheme to philosophy in general and to normative science in particular. For him, philosophy has a threefold division: phenomenology, which simply contemplates the universal phenomenon; normative science, which investigates the universal and necessary laws of the relation of phenomena to ends; and metaphysics, which endeavors to comprehend the reality of phenomena (cf. 5.121). Phenomenology is the Firstness of philosophy, since logicians.

8 This looks very much like the "simple apprehension" of the older

9 It can now be seen how the two degenerate forms of Thirdness are related to Secondness and to Firstness, respectively. The first degree involves the execution of an intention and hence a will act; the second degree involves only the origin of perceptual judgment in a quality of feeling. 
it merely contemplates without judging; it merely looks at and records phenomena as they appear in themselves regardless of anything else. Normative science is the Secondness of philosophy, because it studies the dyadic relation of phenomena to ends and so enables one to form a basis for judging true and false, good and bad, beautiful and ugly. Metaphysics is the Thirdness of philosophy, because it mediates between phenomenology and normative science, between phenomena in themselves and in their relation to ends, by a study of the regularity, law, or efficient reasonableness therein involved.

Reality is an affair of Thirdness as Thirdness, that is, in its mediation between Secondness and Firstness. ... Metaphysics is the science of Reality. Reality consists in regularity. Real regularity is active law. Active law is efficient reasonableness, or in other words is truly reasonable reasonableness.

Reasonable reasonableness is Thirdness as Thirdness. (5.121)

Peirce's division of philosophy, therefore, turns out to be according to his universal categories (5.121-124). And he tells us that if "Normative Science does not seem to be sufficiently described by saying that it treats of phenomena in their secondness, this is an indication that our conception of Normative Science is too narrow ..." (5.125).

After a good deal of hesitation, Peirce's final opinion was that there are three normative sciences: esthetics, ethics (practics), and logic (1.573). This trio relates to feeling, action, and thought, and as such relates to the now familiar categories. Thus esthetics sets up norms concerning qualities of feeling or Firstnesses; ethics or practics sets up norms for judging conduct or Secondnesses; logic sets up norms for deciding what thoughts we should entertain and what arguments we should accept, what procedures we should adopt, that is, norms for Thirdnesses (1.574). Ethics or practics is what Peirce calls the mid-normative science. It is the normative science par excellence, since the phenomena which it examines are Secondnesses (action or conduct) considered in the dyadic relation they form with ends (another level of Secondness). Logic deals with Thirdnesses considered in their dyadic relation to ends (Secondnesses). Reasoning is but a special case of controlled action-controlled action dealing with Thirdnesses and not just with Secondnesses-and so logic is a special 
case of practics. Esthetics presented some difficulty, however, and caused Peirce to hesitate to include it among the normative sciences. How can there be any judgment as to the goodness or badness of a quality of feeling? A quality of feeling is just what it is without regard to anything else. In other words, how is it possible to get a Secondness from a Firstness? On the other hand, experience teaches that men do make evaluative judgments about qualities of feeling. A distinction is made between the esthetically good and the esthetically bad. Is it merely a matter of taste? When we consider in detail the development of Peirce's thinking about esthetics we will be in a better position to know whether these difficulties are resolvable. For the moment, let us just point out that Peirce's final position (and he claimed for it no more than an opinion) was that ethics or practics is a special case or species of esthetics, because somehow or other esthetics deals with the deliberate formation of habits of feeling which ultimately govern deliberate conduct (doing or thinking). It will turn out that while in one sense the phenomena with which esthetics deals are ultimately qualities of feeling (and so esthetics truly relates to Firstness), in another sense esthetics more proximately deals with the formation of habits of feeling (not just an isolated quality) and as such has something of Thirdness or generality about it. Isolated qualities of feeling can be judged good or bad precisely in terms of the habit, which in its turn can be altered, modified or rejected in terms of experience's shock. ${ }^{10}$

What do we have so far in Peirce's architectonic presentation of normative science? Philosophy as a positive science deals with facts -facts gotten from common, ordinary, everyday experience. These facts require no special apparatus to be observed; they are open to any one who will take the time and the effort to become aware of them. On the level of what one does with this data, philosophy divides in three: taking an inventory (phenomenology-Firstness of philosophy), evaluation (normative science-Secondness of philosophy), and comprehension (metaphysics-Thirdness of philosophy). Normative science, of course, is not itself the evaluation of phenomena, but more precisely the theory of such evaluation. It subdivides on another

10 Cf. 5.113; see Part I, Chapter 2. 
level according to the predominant characteristic of the phenomenon studied: quality of feeling (esthetics-Firstness of normative science), action (practics-Secondness of normative science), thought (logic -Thirdness of normative science).

Since, in Peirce's classification of the sciences, logic is again subdivided into three parts and philosophy itself is a member of another trio, one would be led to expect that his universal categories apply to these divisions too. Consider logic. In one place he tells us:

The term "logic" is unscientifically employed by me in two distinct senses. In its narrower sense, it is the science of the necessary conditions of the attainment of truth. In its broader sense, it is the science of the necessary laws of thought, or, still better (thought always taking place by means of signs), it is general semeiotic, treating not merely of truth, but also of the general conditions of signs being signs (which Duns Scotus called grammatica speculativa), also of the laws of the evolution of thought, which since it coincides with the study of the necessary conditions of the transmission of meaning by signs from mind to mind, and from one state of mind to another, ought, for the sake of taking advantage of an old association of terms, be called rhetorica speculativa, but which I content myself with inaccurately calling objective logic, because that conveys the correct idea that it is like Hegel's logic. (1.444)

In another place he says:

We come, therefore, to this, that logic treats of the reference of symbols in general to their objects. In this view it is one of a trivium of conceivable sciences. The first would treat of the formal conditions of symbols having meaning, that is of the reference of symbols in general to their grounds or imputed characters, and this might be called formal grammar; the second, logic, would treat of the formal conditions of the truth of symbols; and the third would treat of the formal conditions of the force of symbols, or their power of appealing to a mind, that is, of their reference in general to interpretants, and this might be called formal rhetoric. (1.559) 
Putting these two passages together, the division of "logic" might be sketched as follows: ${ }^{11}$

Logic in broad sense (normative logic)
Speculative or formal grammar, signs as signs

Logic (in narrow sense), or critic, truth of signs

Speculative or formal rhetoric, or objective logic, communication of signs

Though Peirce himself never applies his categories to this division (at least I found no such passage), it seems reasonably clear that he might have done so with success. Speculative or formal grammar is the Firstness of normative logic, since it deals with signs as signs regardless of anything else. Logic or critic is a plausible candidate for Secondness because it treats of signs as true or false, that is, in their relation to what they signify. Finally, speculative or formal rhetoric fits the category of Thirdness because it treats of signs as communicated, that is, not merely in their relation to what they signify, but for whom they signify.

Philosophy itself is one of the three theoretical sciences of discovery. The other two are mathematics and idioscopy. All three rest upon observation, but they are observational in very different senses (1.239). Mathematics does not undertake to ascertain any matter of fact, but simply posits hypotheses, and traces out their consequences. And yet it is observational

... in so far as it makes constructions in the imagination according to abstract precepts, and then observes these imaginary objects, finding in them relations of parts not specified in the precept of construction. (1.240)

Philosophy deals with "positive truth," but its observations are "such as come within the range of every man's normal experience, and for the most part in every waking hour of his life" (1.241). Idioscopy, too, deals with "positive truth," but the special sciences which make it up depend upon special observation "which travel or other explora-

11 Cf. also $3.430 \mathrm{ff}$. 
tion, or some assistance to the senses, either instrumental or given by training, together with unusual diligence, has put within the power of its students" (1.242). On this basis, a reasonable case can be made that the categories apply at this level of classification of the sciences, as they should, since they are universal. What is required for the observations peculiar to mathematics? Nothing but the "observer's" creative imagination. Mathematics makes no assertions about the actual, existing world of experience, but rather explores the great world of possibility by means of hypothesis and deduction. Mathematics, then, does not logically require anything beyond itself-it is a First. Philosophy, on the other hand, makes categorical statements about reality which claim to be true or false. And according to Peirce its type of observation requires not only imagination, but also experience. Now experience is in the category of Secondness, and so one could say that philosophy is a Second. The special sciences, too, make assertions about the world, and they certainly depend upon experience for their observations. Yet their observations are always mediated. It is not a question of common ordinary experience which is available to all; it is not, so to speak, merely a question of ego confronting non-ego, of observer confronting phenomena. Rather the observer gets to his phenomena through something else-an instrument, a technique, etc. It may be argued, therefore, that the special sciences introduce a Third in their observational procedures, and so qualify as a type of Thirdness, perhaps only degenerate.

This tentative application of the categories to mathematics, philosophy, and idioscopy is at least plausible, and if it, or something like it, be admitted, there is a symmetry in Peirce's architectonic. We have considered the application of the categories only to those sciences with which we are dealing: to philosophy (relative to mathematics and special sciences), to normative science (relative to phenomenology and metaphysics), to the divisions of normative science, and finally to the subdivisions of logic. No doubt, a similar analysis could be made for the other triadic classifications in Peirce's alignment of the sciences. What we notice is that the categories are extremely supple, as indeed they must be if they are truly universal. They can bend or shift just enough to allow their application to different levels of analysis, and yet still keep their shape sufficiently to be readily recognized. They remind one of the act-potency categories of Aristotle 
as used in the scholastic systems where they are applied analogously to different levels of analysis. ${ }^{12}$

While no aspect of a phenomenon can be classified under two categories at the same level of analysis, that same aspect may receive a different classification at another level. Thus, for example, Peirce classifies normative science as Secondness (relative to the other divisions of philosophy); its own subdivisions exhibit all three of the categories. Hence, if one always keeps in mind the level of analysis, the perspective in which Peirce is viewing his subject matter, his use of the universal categories will be found to be more consistent than has sometimes been thought.

12 Take for example their application in Thomistic metaphysics to the orders of existence, essence, and activity, respectively. Basically act means "perfection;" potency "limitation." In the order of existence, esse is act, while essentia is potency. In the order of essence, form is act, while matter is potency. In the order of activity, accident is act, while substance is potency. Nothing can be both act and potency within the same order, but one may well be act in one order and potency in another; e.g. substantial form is act in the order of essence, while essence (and hence substantial form too) is potency in the order of existence.

We are inclined to think that something like this is what Charles Hartshorne has in mind when he distinguishes the "relatively absolute" from the "absolutely absolute." Firsts and Seconds of experience are only "relatively absolute," relative to a context. Cf. "The Relativity of Nonrelativity," Studies in the Philosophy of Charles Sanders Peirce, ed. by Wiener and Young (Cambridge: Harvard University Press, 1952), pp. 219 ff. and "Charles Peirce's 'One Contribution to Philosophy' and His Most Serious Mistake," Studies, Moore and Robin, pp. $459 \mathrm{ff}$. 